Textures and Microstructures, Vol. 33, pp. 279-289 Reprints available directly from the publisher Photocopying permitted by license only
(C) 1999 OPA (Overseas Publishers Association) N.V.

Published by license under the Gordon and Breach Science Publishers imprint. Printed in Malaysia.

\title{
RESIDUAL STRESS INVESTIGATIONS IN AUSTENITIC STEEL SAMPLES WITH DIFFERENT DEGREE OF LOW CYCLE FATIGUE
}

\author{
G.D. BOKUCHAVA ${ }^{\mathrm{a}, *}$, V.V. LUZIN $^{\mathrm{b}}$, J. SCHREIBER $^{\mathrm{c}}$ \\ and YU.V. TARAN ${ }^{b}$ \\ a Institute for Nuclear Research of RAS, 117312 Moscow, Russia; \\ ${ }^{b}$ Frank Laboratory of Neutron Physics, JINR, 141980 Dubna, Russia; \\ ${ }^{c}$ Fraunhofer Institute for Nondestructive Testing, 01326 Dresden, Germany
}

\begin{abstract}
Austenitic stainless steels are widely used because of their high corrosion resistance and toughness. The influence of the applied cyclic load on the mechanical properties of the material is of great current interest. In order to investigate residual stress evolution a series of the austenitic steel samples (X6CrNiTi1810) with different degrees of low cycle fatigue was studied. Martensitic phase formation was observed at different degrees of low cycle fatigue. Residual stresses, microstresses in both phases, as well as martensitic precipitation volume fractions, were estimated. Usually after plastic deformation the martensite phase produces a structure of oriented plates or laths. Therefore martensite texture formation during phase transition can be expected. Indeed the registered neutron diffraction spectra from austenitic fatigued samples show texture presence and its variation in dependence of the fatigue degree. The attempt to consider the texture evolution in dependence of fatigue degree and its influence on the residual stresses was made.
\end{abstract}

Keywords: Elastic constants; Residual stress; Texture; Phase transition

\section{INTRODUCTION}

Austenitic stainless steels are widely used in engineering because of their high corrosion resistance and toughness. Internal mechanical stresses in steel components occur after fabrication process, external load during

\footnotetext{
* Corresponding author.
} 
exploitation, mechanical and thermal treatment. Therefore it is necessary to control stress level in a material at various load regimes. In this connection the special interest represents study of such mechanical properties of austenitic steel as a creep, martensitic phase formation, mechanical and thermal fatigue, fatigue failure due to cyclic load, plastic deformation, and texture influence on elastic properties.

This paper reports on the elastic property investigations of austenitic steel under applied load as well as studies of residual stresses occurring due to low cycle fatigue of the material. The attempt to consider the texture evolution in dependence of fatigue degree and its influence on residual stresses was also made. The material examined was the austenitic stainless steel X6CrNiTi1810 of the following content (wt\%): C $0.04, \mathrm{Si}-0.44, \mathrm{Mn}-1.14, \mathrm{P}-0.033, \mathrm{~S}-0.004, \mathrm{Cr}-17.74, \mathrm{Ni}-19.3, \mathrm{Ti}$ -0.35 . The residual stress measurements were carried out on the high resolution Fourier diffractometer $\operatorname{HRFD}\left(\Delta d / d \approx 1 \times 10^{-3}\right)$ at the IBR2 pulsed reactor (Aksenov et al., 1993). The texture experiments were performed on NSHR texture diffractometer (Anajev et al., 1984).

\section{NEUTRON ELASTIC CONSTANTS}

Elastic properties depend on the state of material, chemical composition, microstructure and mechanical and thermal treatment. Therefore it is necessary to determine experimentally the elastic constants for the studied material. Foremost in our experiment, neutron elastic constants for investigated austenitic steel were determined by neutron diffraction method. The sample of the austenitic steel was subjected to the applied load in situ in the neutron beam, using a special purpose loading device. The elastic strain was measured for different crystal planes $(h k l)$ with scattering vector $\boldsymbol{Q}$ direction parallel and perpendicular to the applied load (Fig. 1). Strain in parallel direction was measured at the scattering angle $2 \theta=90^{\circ}$, in perpendicular direction - at the scattering angle $2 \theta=152^{\circ}$. Moreover, average strain was determined independently by extensiometers from relative changes of sample dimensions. For all registered spectra separate diffraction peak positions and widths were determined. Strains for all available crystal planes $(h k l)$ were obtained from relative shift of diffraction peaks. Also diffraction spectra were processed by Rietveld profile refinement method. In this case strain 

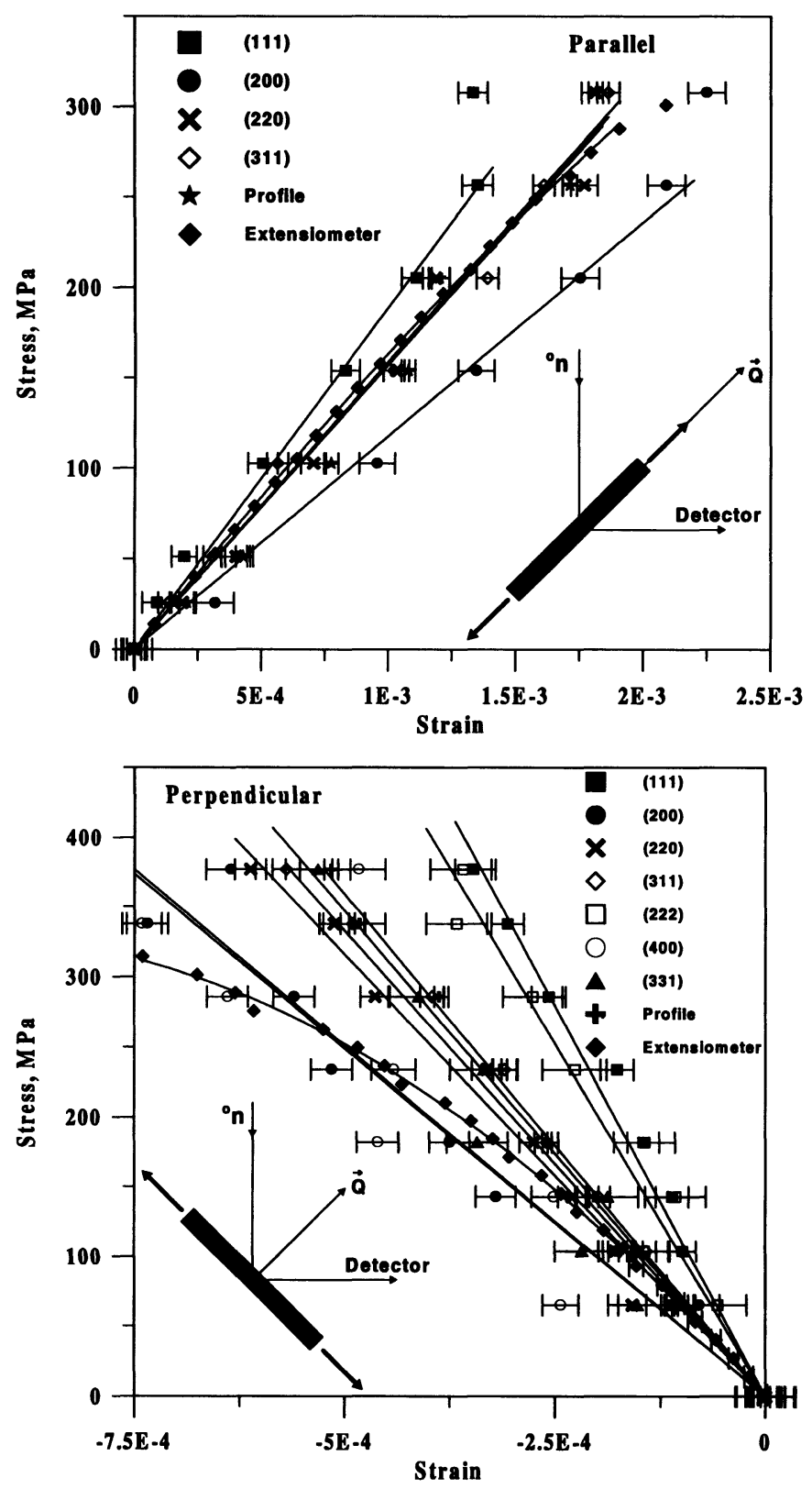

FIGURE 1 Lattice strain parallel and perpendicular to applied load. 
averaged on all crystallographic directions $[h k l]$ and corresponding to the anisotropy factor $\Gamma_{h k l}=0.2$ were obtained from lattice parameter changes.

In plastic region (at the applied stress level over $\sim 250 \mathrm{MPa}$ ) strain registered by extensiometers deviates from linear dependence. On the contrary strain obtained from neutron diffraction data does not show strong deviation from linear dependence. At that a width of diffraction peak increases significantly (Fig. 2). Such behavior of diffraction peak is typical for plastic deformation.

In elastic region the elastic modules $E_{h k l}^{\|}$and $E_{h k l}^{\perp}$ as a function of the anisotropy factor,

$$
\Gamma_{h k l}=\frac{\left(h^{2} k^{2}+h^{2} l^{2}+k^{2} l^{2}\right)^{2}}{\left(h^{2}+k^{2}+l^{2}\right)^{2}},
$$

were obtained from the slopes of the strain-stress linear dependencies (Fig. 3). The elastic constants $S_{11}, S_{12}$ and $S_{44}$ were calculated in the frame of the Hill model (Hill, 1952) which assumes taking of an arithmetic average of the Reuss and Voigt model values and gives the results very close to the Kröner model values. Thus, the following values were

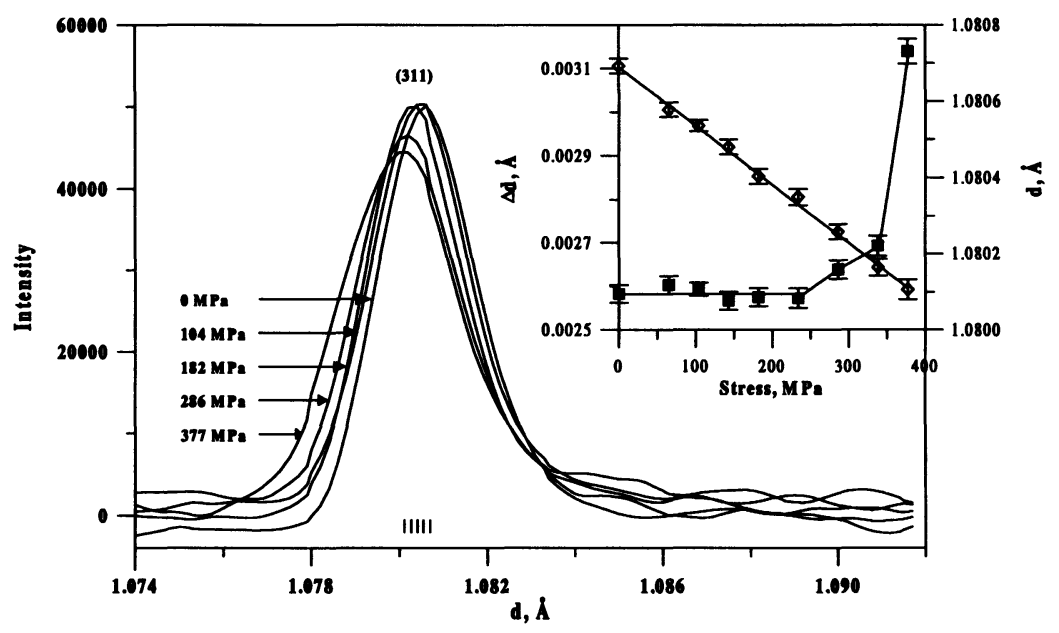

FIGURE 2 Bragg reflection (311), position, and width changes versus applied load. The strain was measured perpendicular to the applied load. 


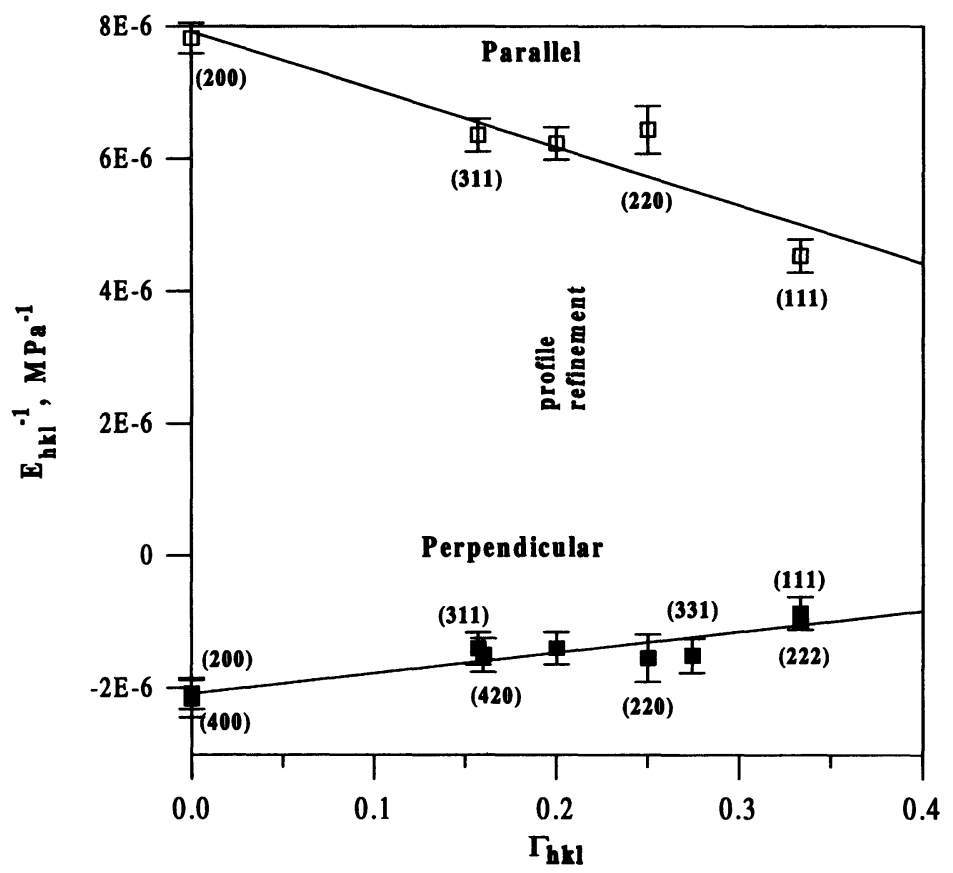

FIGURE 3 Dependence of the elastic modules $E_{h k l}^{\|}$and $E_{h k l}^{\perp}$ parallel and perpendicular to the applied load.

obtained for the material investigated: $S_{11}=6.70 \times 10^{-6} \mathrm{MPa}^{-1}, S_{12}=$ $-2.24 \times 10^{-6} \mathrm{MPa}^{-1}$, and $S_{44}=12.43 \times 10^{-6} \mathrm{MPa}^{-1}$.

\section{AUSTENITIC STEEL SAMPLES WITH DIFFERENT DEGREE OF LOW CYCLE FATIGUE}

The influence of applied cyclic load on the material mechanical properties is of great current interest. In order to investigate residual stress evolution a series of the austenitic steel samples with different degrees of low cycle fatigue were studied. The cylindrical samples produced from austenitic stainless steel X6CrNiTi1810 (see above) were subjected to a number of tensile-compressive loading cycles with a maximum plastic deformation of $\pm 0.6 \%$ at the frequency of $0.1 \mathrm{~Hz}$. A number of cycles corresponding to the sample failure was determined experimentally, $N_{\max } \approx 1020$. 
As it is well known, as a result of thermal treatment or plastic deformation, austenitic stainless steel undergoes a phase transition to the tetragonal martensitic phase. The tetragonal distortion value for the martensitic structure depends strongly on the carbon content (Roberts, 1953). In our experiment due to a low carbon content only the diffraction peaks characteristic for a martensitic cubic structure were registered. The residual strain for both phases was measured in the longitudinal and radial directions (Fig. 4).

Usually martensitic phase growth starts at the grain boundaries of the initial austenitic structure after plastic deformation. At that the martensite phase produces a structure of oriented plates or laths. Therefore, martensite texture formation during phase transition can be expected. Indeed the registered neutron diffraction spectra from austenitic fatigued samples show texture presence (Fig. 5) and its variation in dependence of the fatigue degree (Fig. 6).

More detailed researches were done to describe quantitatively the texture evolution in dependence of the fatigue degree and its influence on the residual stress distribution. Texture changes in both austenitic

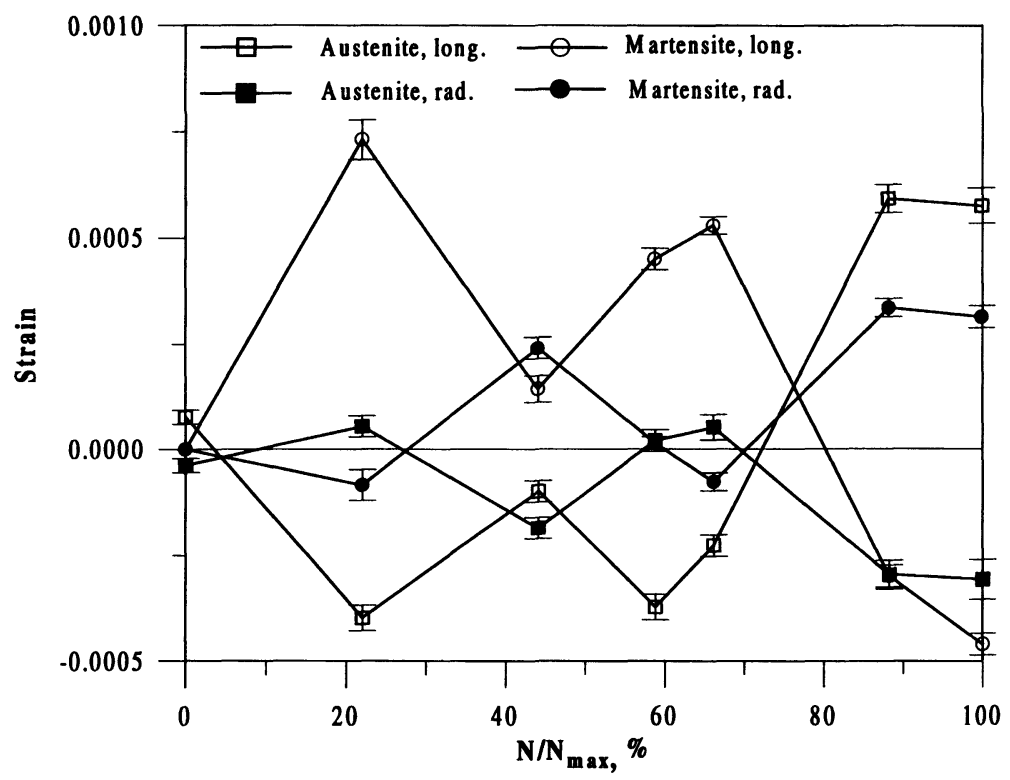

FIGURE 4 Residual strain in austenite and martensite versus the fatigue degree. 


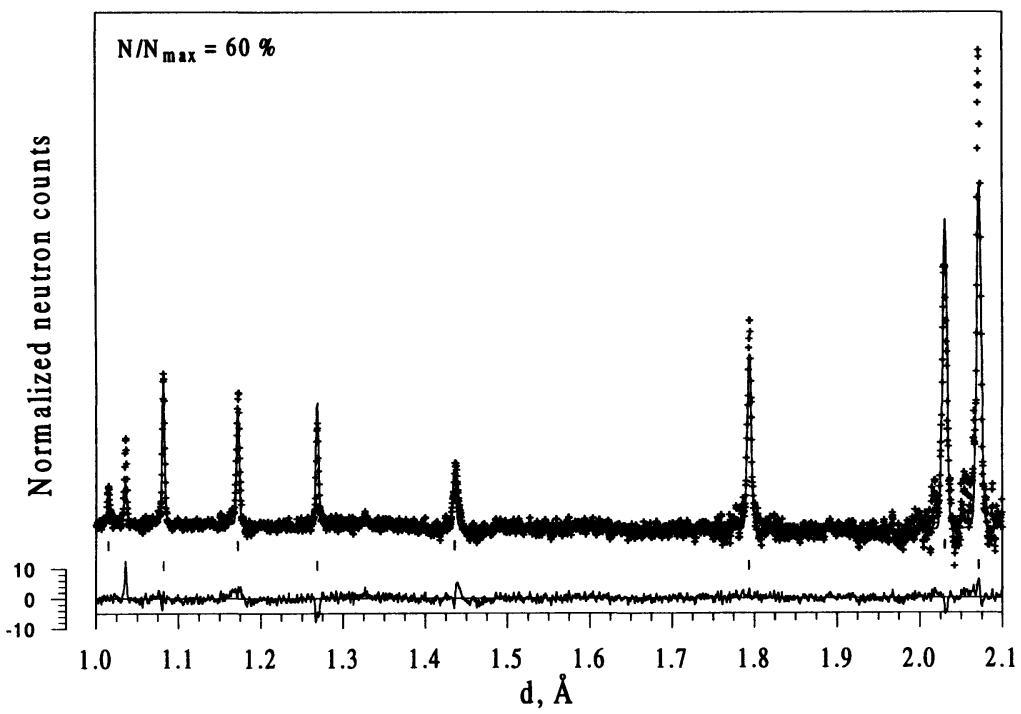

FIGURE 5 A part of the neutron diffraction pattern from austenitic steer with fatigue degree of $60 \%$. Experimental points, profile calculated by the Rietveld method and difference curve normalized by means of square deviations of the experimental points are shown. The tick marks (from top down) are calculated peak positions for martensitic and austenitic phases, respectively.

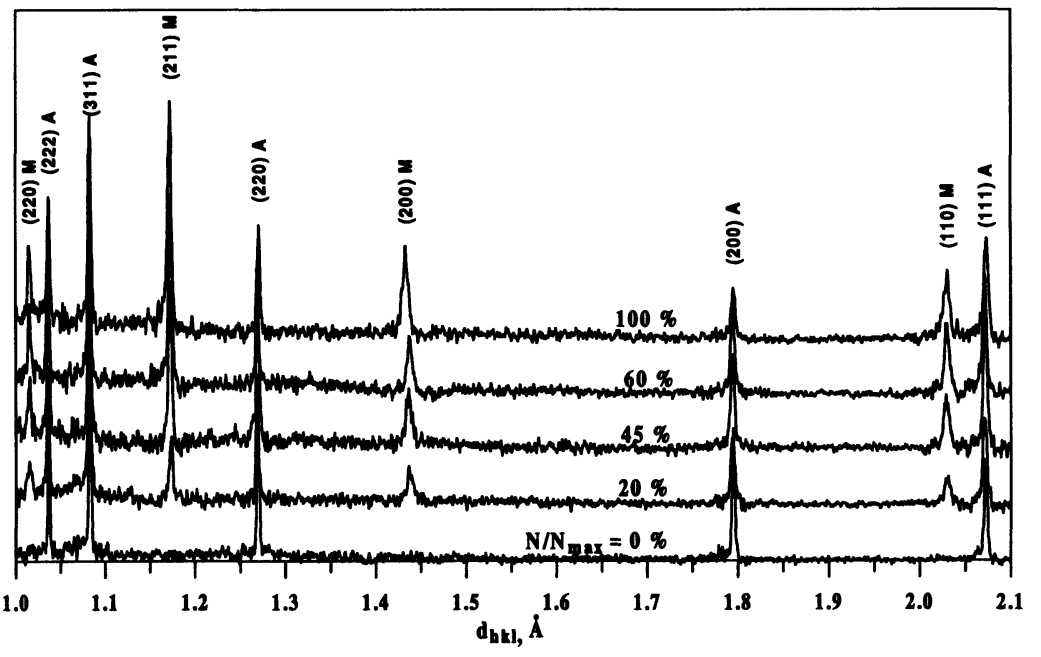

FIGURE 6 Neutron diffraction pattern evolution versus fatigue degree. 
and martensitic phases are shown in Fig. 7. The pole figures reconstructed by Bunge method are presented. The dependence of the texture index versus the fatigue degree is shown in Fig. 8 to characterize quantitatively the texture evolution. It should be concluded that the martensite phase substitutes the austenite phase with descent of the texture features at the early stage. Further behavior of these two phases is contrary with respect to the texture index rate.

Results of texture measurements can be used for the determination of volume fraction on the various stages of fatigue process. In Figs. 9 and 10 martensite and austenite volume fraction estimates from the Rietveld profile refinement and texture measurements are compared. In both cases an increase in the martensite volume fraction was observed on an increase in the cycle fatigue degree $N / N_{\max }$.

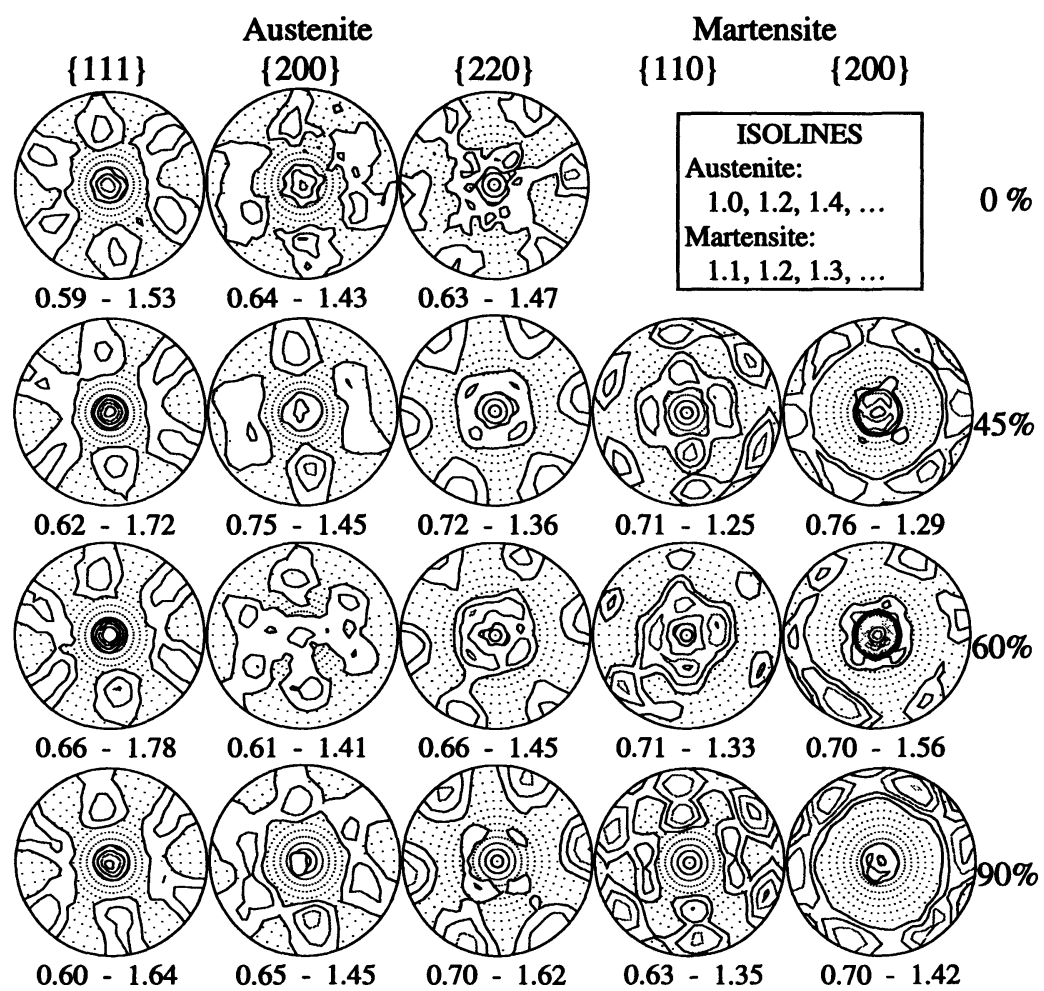

FIGURE 7 Austenite and martensite texture evolution versus fatigue degree. 


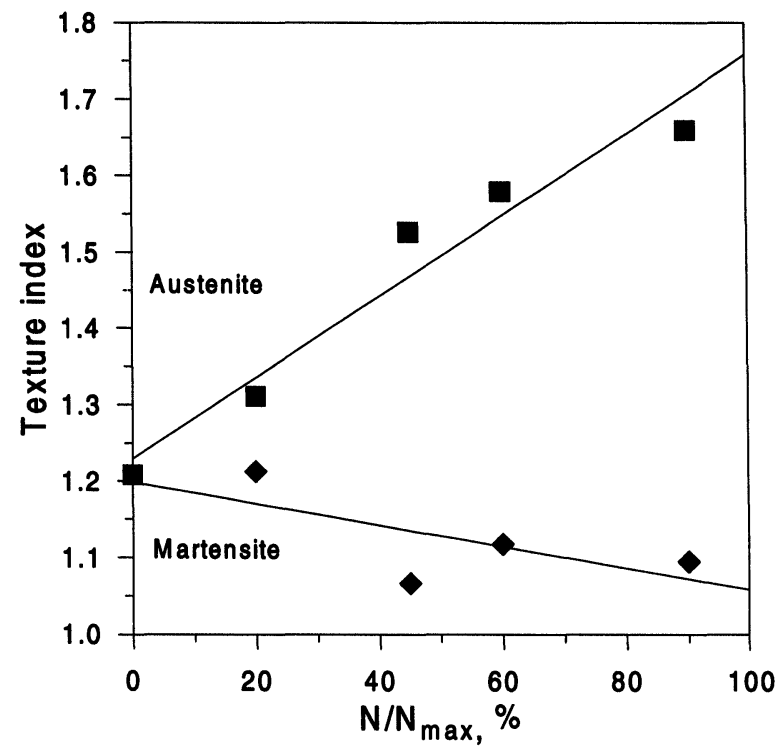

FIGURE 8 Dependence of the texture index reconstructed by Bunge method for austenite and martensite versus the fatigue degree.

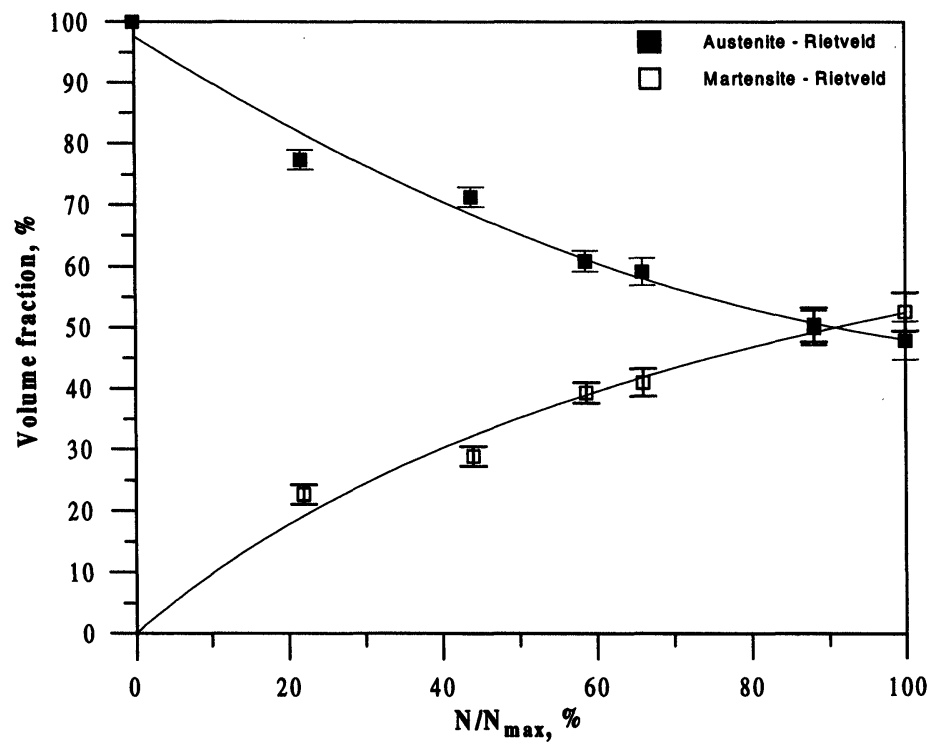

FIGURE 9 Dependence of austenitic and martensitic volume fractions versus the fatigue degree. Volume fractions were estimated from profile refinement. The lines serve as a guide for the eye. 


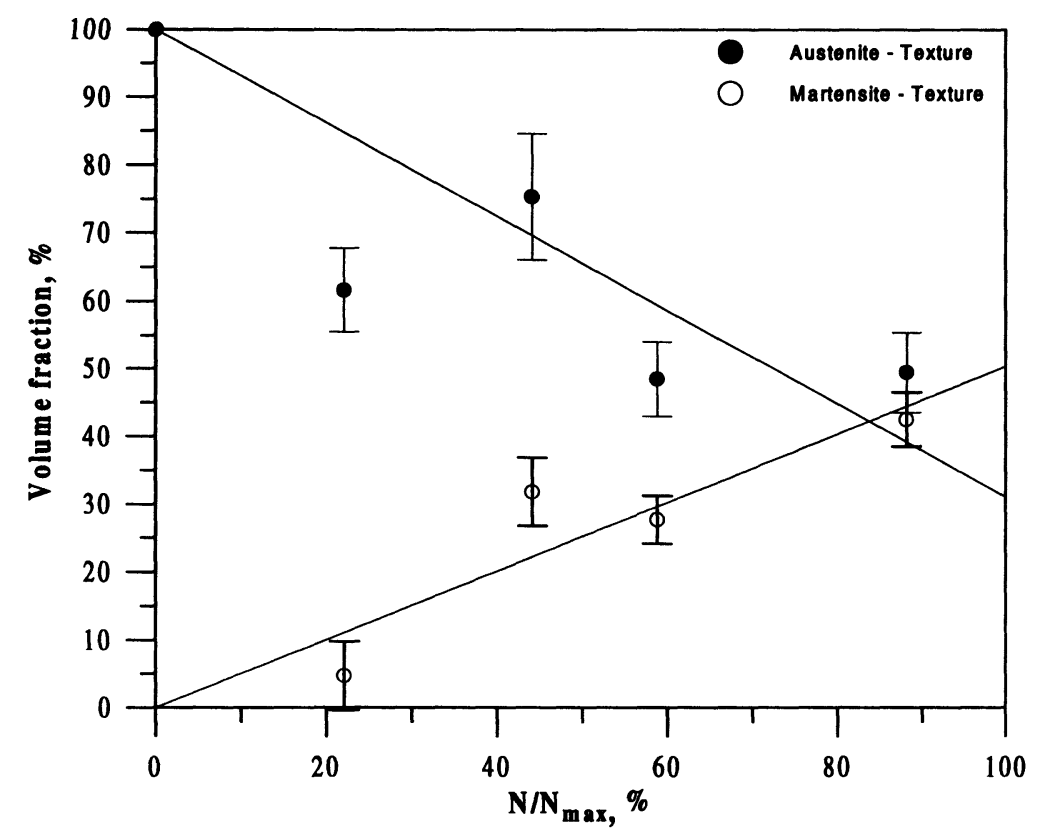

FIGURE 10 Dependence of austenitic and martensitic volume fractions versus the fatigue degree. Volume fractions were estimated from texture measurements. The lines serve as a guide for the eye.

In spite of aforesaid the texture in both phases is rather weak. Therefore it is not necessary to take into account texture influence in the stress-from-strain calculations, especially for materials obeying cubic symmetry. It was assumed that the stress field distribution in the sample has the cylindrical symmetry. The stresses calculated from the (311) and (220) reflections for austenite and martensite, respectively, are shown in Fig. 11. For an austenitic matrix, the elastic constants determined from the previous experiment were used and for martensite were taken from the literature (Bollenrath et al., 1967). It is necessary to note that stresses in austenite are mainly compressive while stresses in the martensite phase are tensile.

The analysis of diffraction peak broadening points to partial relaxation of the estimated microstresses as the fatigue degree increases. Most likely this phenomenon is connected to growth of microcracks in the bulk of the material. In comparison with austenite, for a more brittle martensitic phase this effect is more pronounced. 


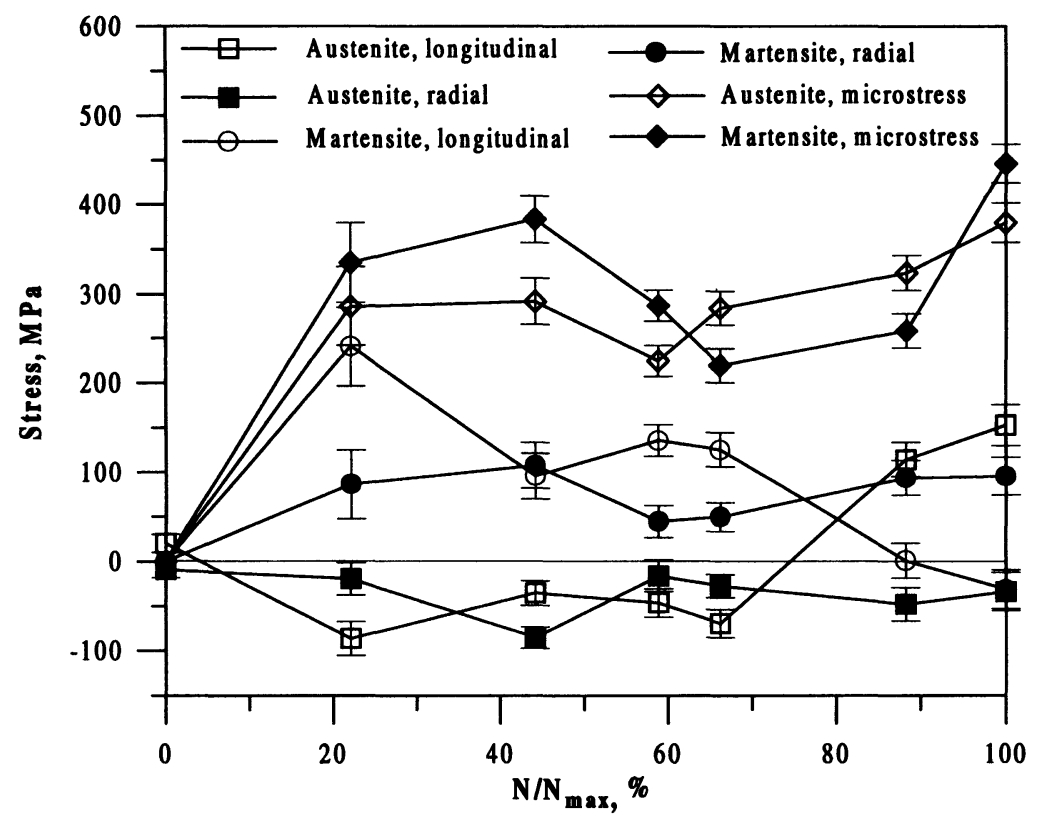

FIGURE 11 Phase stresses and microstresses versus the fatigue degree.

\section{References}

Aksenov, V.L., Balagurov, A.M., Simkin, V.G., Taran, Yu.V., Trounov, V.A. and Kudrjashev, V.A. et al. (1993). Proc. of XII Meeting of the Intern. Collaboration on Advanced Neutron Sources (ICANS-XII), Abingdon, 1, 124.

Anajev, B.N., Betzl, M., Bede, W., Walther, K., Voronov, B.I. and Goremychkin, E.A. et al. (1984). JINR Communication, Dubna, P14-84-827.

Bollenrath, F., Hauk, V. and Müller, E.H. (1967). Z. Metallkunde., 58, 76.

Hill, R. (1952). Proc. Phys. Soc., A65, 349-354.

Roberts, C.S. (1953). Trans. AIMME, 197, 203. 